\title{
INVESTIGATION OF THERMAL BEHAVIOR OF NIGELLAE SATIVAE SEMEN FROM DIFFERENT TYPES OF EXTRACTS
}

\author{
CLAUDIA-CRINA TOMA ${ }^{\mathrm{a} * *}$, BOGDAN TITA ${ }^{\mathrm{a}}$, \\ NELI-KINGA OLAH ${ }^{a, b}$, GIANCARLO STATTI ${ }^{c}$
}

\begin{abstract}
Thermal methods have an important applicability in the pharmaceutical field, such as raw material control, purity determination, thermal stability determination, substance compatibility, qualitative and quantitative analysis of drugs, etc. Data on substance stability are obtained from the analysis of thermal decomposition determinations that occur both under isothermal conditions and under non-isothermal conditions. Thermogravimetry and derived thermogravimetry (TG / DTG) and differential scanning calorimetry (DSC) that are used to study the compatibility of the active substances and excipients have become increasingly important, because identify possible interactions between these components of the drugs. These thermoanalytic techniques have been used to study the behavior of a Nigella sativa semen glycerin macerate. To obtain tinctures and glycerin macerates, the European Pharmacopoeia methodology was followed. The thermoanalytic curves were recorded in a dynamic atmosphere of nitrogen and air $(20 \mathrm{ml} / \mathrm{min})$. The sample heating rate was $10^{\circ} \mathrm{C} / \mathrm{min}$. Thermal TG / DTG and DSC methods were applied in the temperature range of $25-1000^{\circ} \mathrm{C}$.
\end{abstract}

Keywords: Nigella sativa semen, thermogravimetry, differential scanning calorimetry

a VasileGoldis Western University of Arad, Faculty of Pharmacy, 86 L. Rebreanu str., RO310414, Arad, Romania

b SC PlantExtrakt SRL, 407059-Rădaia, Jud. Cluj, Romania

c Department of Pharmacy, Health and Nutritional SciencesUniversity of Calabria, Arcavacata di Rende, 87030, Italy

* equal contribution

*Correspondent author: claudiatoma2004@yahoo.com, 


\section{INTRODUCTION}

An important plant from the ethnobotanical tradition of Northern Afrika is Nigella sativa, Ranunculaceae family, named also black cumin. It is considered one of the most used spice of the muslims, cited in the Coran because of its seeds. Seeds are the vegetal product used by Nigella genus in traditional medicine. The seeds are small, black, with a lot of therapeutic indications but also with toxicological activity [1].

The use of extracts, instead of isolated active principles, makes it possible to exploit the synergies of action between the multiple compounds from phytocomplex. This, however, requires the assessment of thermal stability, also in relation to possible interactions between the present compounds.

One of the frequently used analytical method in pharmaceutical research is the thermal analysis, meaning the study of thermal stability and the substances' decomposition. This method is used for the thermal characterization of all solid and semi-solid substances that are used in the pharmaceutical industry[2,3].

It is very important to determine the temperature range in which the pharmaceutical substance is thermally stable. If are stored at these temperature, the substances will maintain their chemical structure and implicit their pharmaceutical actions. The technological transformations must take place at these temperatures in order to obtain the good quality pharmaceutical products $[4,5]$.

The study of the thermal stability of pharmaceutical products takes place by analyzing the decomposition of the substances under isothermal and non-isothermal conditions. Drug decomposition occurs through the loss of irreversible mass. Reactions to drug decomposition are of theoretical and practical importance. From high-temperature research, when the processes are accelerated, the data obtained provides the rate of degradation of drugs at marketing temperatures $[6,7]$.

The analytical methods have been used to characterize compounds also from herbal medicine. Thermal analysis, infrared spectroscopy, and Xray diffraction are examples of methods used for characterizing drugs and herbal medicines [6].

Thermogravimetric method is a reproducible method that has a high sensitivity and provides a rapid response regarding the mass variations that occur. The results obtained from thermogravimetry are related to the thermal stability and composition of the sample [8]. 
Differential scanning calorimetry is used in pharmaceutical research as a very important analytical method for identifying and determining the purity of active substances, but especially for obtaining information on compatibility of substances and how are they affected by thermal processes $[6,8]$.

Such techniques have attracted a particular interest of researchers because they can also be used to characterize medicinal products of both natural and synthetic origin, but also food, polymers or cosmetics [9].

In other articles we have presented the usefulness and importance of thermal analysis in determining the thermal stability and the compatibility of different pharmaceuticals by thermal behavior. [10,11].

In this article we intend to characterize Nigella sativa semen by thermal methods, thus obtaining information that will be used to obtain natural products used for medicinal purposes. This study proposed investigations in the field of thermal stability of Nigellae sativae semen extracts, from vegetal material harvested from Tunisia, in 2015.

\section{RESULTS AND DISCUSSIONS}

The thermal behavior of tincture in the two working atmospheres, air and nitrogen is virtually the same. This was to be expected and the thermoanalytic curves of Figs. 1 and 2 show this.

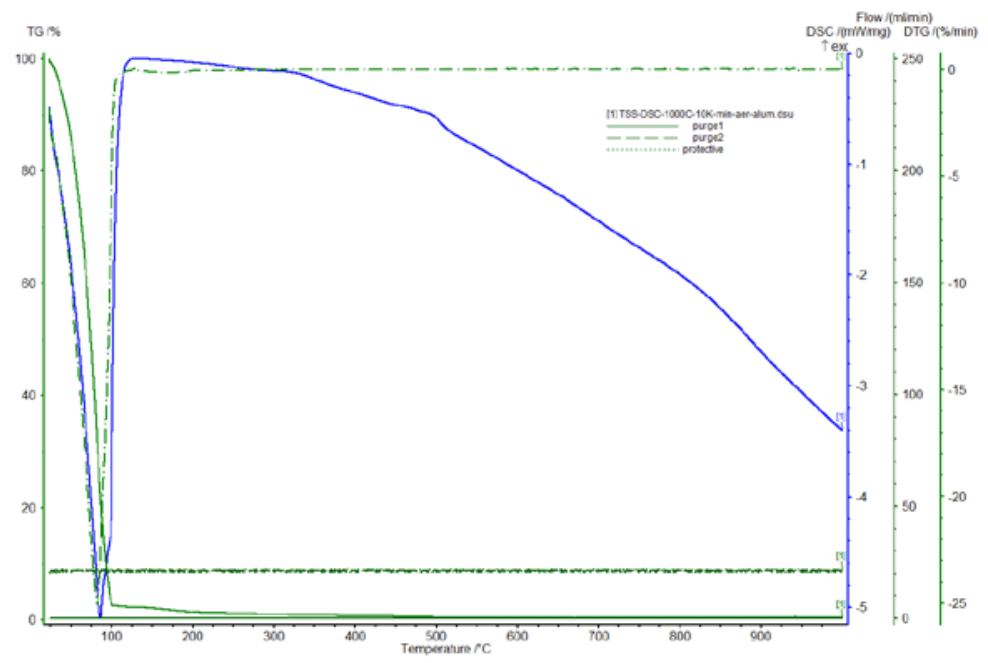

Figure 1. Thermoanalytical curves of the Nigella sativa semen tincture (air atmosphere) 


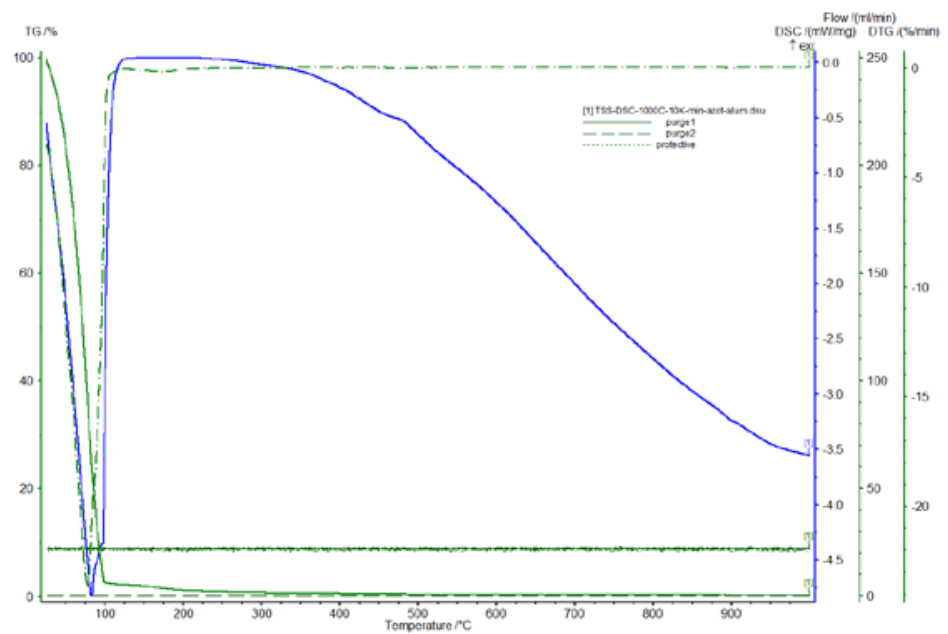

Figure 2. Thermoanalytical curves of the Nigella sativa semen tincture (nitrogen atmosphere)

The TG / DTG curves show a single decomposition step, which is well-defined and it takes part $25-125.0^{\circ} \mathrm{C}$ respectively $125.0^{\circ} \mathrm{C}$ in nitrogen atmosphere with a mass loss of $97.8 \%$. Then there is a very slow mass loss (2.20\%), so at $450.0^{\circ} \mathrm{C}$ the residual mass is zero and $\mathrm{T}_{\text {peak DTG }}$ is $84.2^{\circ} \mathrm{C}$ respectively $84.6^{\circ} \mathrm{C}$ (in nitrogen atmosphere).

The DSC curves showed that thermal processes occur between the mentioned temperatures. The presence of one endothermic event at $85.8^{\circ} \mathrm{C}$ respectively $85.2^{\circ} \mathrm{C}$ was observed, which is related to the loss of volatile constituents of the sample.

As for the glycerin macerates of Nigellae sativae semen, their thermal behavior in air and nitrogen is partly different. This is especially evident on the DSC curves presented in Figures 3 and 4.

The temperature range at which the decomposition takes place in the air is $25.0-269.0^{\circ} \mathrm{C}$ with two successive stages. These stages are very difficult to delimit. The temperature range for the first stage is $25-156^{\circ} \mathrm{C}$ with $\mathrm{T}_{\text {peak DTG }}$ at $84.6^{\circ} \mathrm{C}$ The loss of mass for this first stage is $30.0 \%$ and the thermal process is accompanied by an endothermic effect on the DSC curve, with $T_{\text {peak }}$ Dsc at $92.3{ }^{\circ} \mathrm{C}$. The thermal effect corresponds to the loss of the volatile constituents of the sample. The second thermal process, the main one, corresponds to the temperature range $156.2-269{ }^{\circ} \mathrm{C}$, with $\mathrm{T}_{\text {peak DTG }}$ at 264.6 ${ }^{\circ} \mathrm{C}$ and $\Delta \mathrm{m}=68.9 \%$, so at $\approx 350^{\circ} \mathrm{C}$ the residual mass is zero. For this process, a component volatilization, the DSC curve presents a sharp endothermic peak, with $\mathrm{T}_{\text {peak DSC }}$ at263.8 ${ }^{\circ} \mathrm{C}$. 


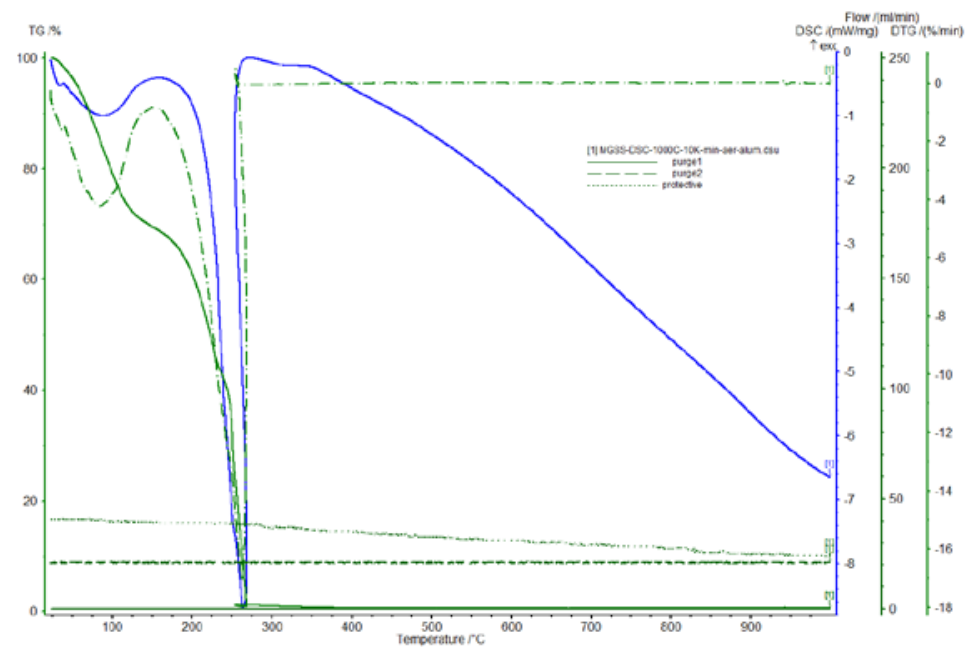

Figure 3. Thermoanalytical curves of the Nigella sativa semen glycerin macerate (air atmosphere)

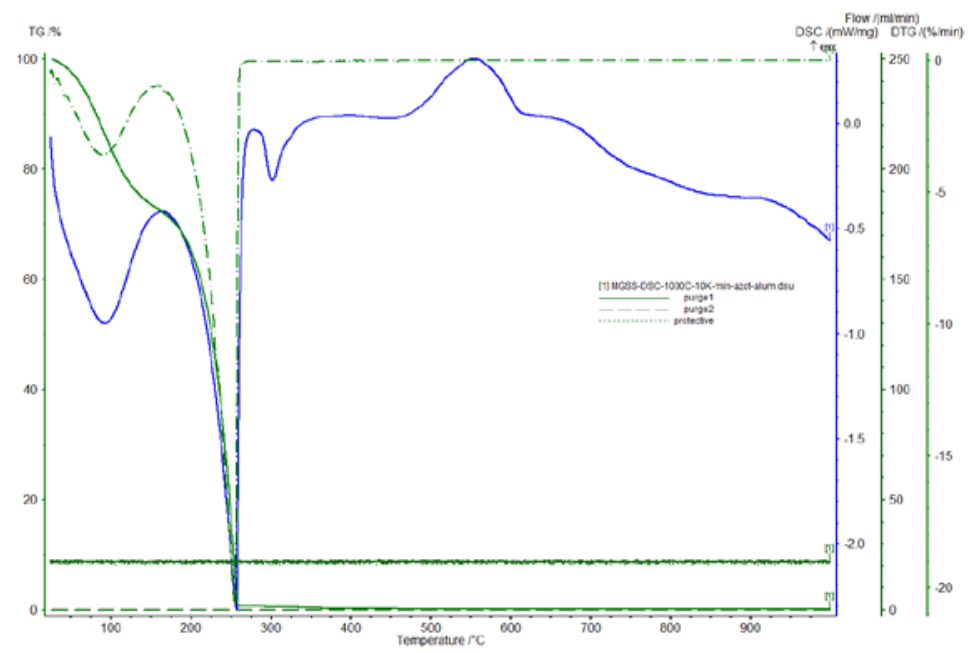

Figure 4. Thermoanalytical curves of the Nigella sativa semen glycerin macerate (nitrogen atmosphere)

Regarding nitrogen decomposition, the differences are insignificant for the actual air decomposition part (the first two thermal processes), e.g.: $159.2^{\circ} \mathrm{C}$ instead of $156.2^{\circ} \mathrm{C} ; 269.2^{\circ} \mathrm{C}$ instead of $269^{\circ} \mathrm{C} ; 257.7^{\circ} \mathrm{C}$ instead of $264.6^{\circ} \mathrm{C}$ and $263.8{ }^{\circ} \mathrm{C} ; \Delta \mathrm{m}_{1}=27.9 \%$ instead of $30 \% ; \Delta \mathrm{m}_{2}=70.9 \%$ instead of $68.9 \%$. 
Moreover, the thermal decomposition occurs with formation of several endothermic $\left(T_{\text {peak DSC }}=300^{\circ} \mathrm{C}\right)$ and exothermic $\left(T_{\text {peak DSC }}=553.8^{\circ} \mathrm{C}\right)$ peaks. This decomposition may be associated with a wide variety of secondary metabolites, principally phenolics, present in the extract.

\section{CONCLUSIONS}

The pharmaceutical industry disposes of valuable tools used for quality control of products and raw materials. These tools can be used for products of plant origin, which also require characterization. Because Nigellae sativae semen is conditioned in dietary supplements, with huge importance for different types of therapies, the quality of the products is very important.

This work showed the application of thermal analysis on a vegetalderived raw material, obtaining results which provide important information about its stability, standardization, composition, crystalline conformation, etc. This information can be used to establish parameters on the development of phytotherapic products, helping to insure its quality and, therefore, its safety and efficacy.

The main conclusion of this study is that the glycerin macerates show higher stability compared to tincture.

In addition to the kinetic study applications for the assessment of drug stability, including the determination of time and storage conditions, another practical application is the determination of drug stability time(s). It is known that with the classic stability test it takes months or even years, whereas with thermal analysis this is solved in a very short time. Thus, we can determine: lifetime under certain environmental conditions (the time period for which a drug keeps its activity); half-life time; shelf-life time (the amount of time that isothermal decomposition of a small amount of product is preset).

The determination of the above-mentioned times is done by heating the sample and speeding up the decomposition process so that their values should be interpreted with caution at room temperature.

Among the various methods of active substance-excipient compatibility studies, the DSC method is increasingly regarded as an important tool at the beginning of the preformulation study of any solid dosage form to obtain rapid information on possible interactions between the formulation components.

Possible interactions between components are obtained or deduced from the DSC curves by the occurrence, modification or disappearance of DSC peaks, especially the DSC melt peak, and/or variations in the assumed enthalpy values $(\Delta \mathrm{H})$. Interaction results in a decrease or increase in $\Delta \mathrm{H}$ in the case of overlapping is a more complex process. 


\section{EXPERIMENTAL PART}

\section{Materials and methods}

The Nigellae sativae semen was harvested from Tunisia, in June 2015, identified in the laboratory of the Pharmacognosy- "VasileGoldis" Western University of Arad, Faculty of Pharmacy. One voucher specimen was maintained in the herbary of the laboratory.

The tincture was prepared using one part of raw material (Nigellae sativae semen) for ten parts of alcohol $70 \mathrm{v} / \mathrm{v}$ macerated for 7 days, than pressed and filtered. For obtaining the hydro-glycero-alcoholic extract one part of the raw material must be macerated 21 days in twenty parts of solvent (1:1 alcohol $96 \mathrm{v} / \mathrm{v}$ and glycerine). Nigellae sativae semen must be minced in order to extend the surface of the raw material for a good extraction.

Thermogravimetry consists in recording the sample mass by temperature or time $\left(m=f(T) ; m=f^{\prime}(t)\right)$ as the sample temperature increases linearly over time. Graphical representation of mass or mass percentage by temperature or time is the thermogravimetric (TG) or thermogram curve.

Therefore, in TG, the mass of the sample is continuously measured in a crucible, heated in an oven, in a programmed temperature, in an atmosphere that can be controlled or set by the introduction of a gas. Mass measurements are made using an analytical balance included in a thermogravimetric analyser.

The principle of the DSC method during heating or cooling is to measure the enthalpy or heat flux difference between the test sample and the reference substance during heat treatment.

The TG/DTG and DSC curves were made with a Netzch-STA 449 TG/DTA apparatus manufactured by Netzch Geratebau GMBH, Germany, under the following conditions:

- temperature range $25-1000^{\circ} \mathrm{C}$ - heating rate $(\beta): 10^{\circ} \mathrm{C} / \mathrm{min}$;

- platinum crucible;

- sample mass: $\approx 22 \mathrm{mg}$;

- atmosphere: Nitrogen stream with a flow rate of $20 \mathrm{~mL} / \mathrm{min}$ 


\section{REFERENCES}

1. J. Bellakhdar, La Pharmacopee marocaine traditionnelle, Ibis Press, 1997, 457.

2. B. Tita, C. Morgovan, D. Tița, T. A. Neag, Revista de Chimie, 2016, 67(1), 38.

3. F.H.A. ernandez, C.P. Santana, R.L. Santos, L.P. Correia, R.O.Macedo, Journal of Thermal Analysis and Calorimery 2013, 113, 443.

4. B. Tita, E. Marian, G. Rusu, G. Bandur, D. Tita, Revista de Chimie. Bucharest, 2013, 64 (12), 1390.

5. R.S. da Costa, Ch.A.B. NegraoS.R.P. Camelo, W.L.R. Barbosa, J.O.L. Silva Junior, Journal of Thermal Analysis and Calorimetry, 2013, 111, 1959.

6. B. Tita, T. Jurca, G. Rusu, G. Bandur, D. Tita, Revista de Chimie Bucharest, 2013, 64(10), 1089.

7. L.P.Correia, C.P. Santana, A.C.D. Medeiros, R.O. Macedo, Journal of Thermal Analysis and Calorimetry, 2015, 123(2), 993.

8. L.P. Correia, C.P. Santana, M.F. Pinto, A.F.O. Santos, R.O. Macedo, Journal of Thermal Analysis and Calorimetry, 2015, 122(1), 207.

9. N. Chirani, H. Yahia, L. Gritsch, F.L. Motta, S. Chirani, S. Fare, Journal of Biomedical Science, 2015, 4, 2.

10. E. Marian, N. Duteanu, L. Vicas, B. Tita, P. Sfirloaga, T. Jurca, Revista de Chimie Bucharest 2017, 68(7), 1435.

11. C.C. Toma, T.A. Neag, B. Tita, Revista de Chimie. Bucharest, 2017, 68(5), 1007. 